This item was submitted to Loughborough's Research Repository by the author.

Items in Figshare are protected by copyright, with all rights reserved, unless otherwise indicated.

\title{
Proton transport enabled by a field-induced metallic state in a semiconductor heterostructure
}

PLEASE CITE THE PUBLISHED VERSION

https://doi.org/10.1126/science.aaz9139

\section{PUBLISHER}

American Association for the Advancement of Science

\section{VERSION}

AM (Accepted Manuscript)

\section{PUBLISHER STATEMENT}

This is the author's version of the work. It is posted here by permission of the AAAS for personal use, not for redistribution. The definitive version was published in Science on 369(6500), pp. 184-188, 10/07/20, DOI: 10.1126/science.aaz9139

\section{LICENCE}

CC BY-NC-ND 3.0

\section{REPOSITORY RECORD}

Wu, Y, B Zhu, M Huang, L Liu, Q Shi, M Akbar, C Chen, et al.. 2020. "Proton Transport Enabled by a Fieldinduced Metallic State in a Semiconductor Heterostructure". Loughborough University. https://hdl.handle.net/2134/14046914.v1. 


\title{
Title: Proton transport enabled by a field-induced metallic state in a semiconductor heterostructure
}

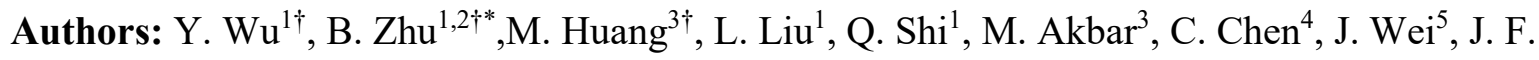

\author{
Li $^{5}$, L. R. Zheng ${ }^{6}$, J. S. Kim ${ }^{7}$, H. B. Song ${ }^{1 *}$
}

\section{Affiliations:}

${ }^{1}$ Engineering Research Center of Nano-Geo Materials of Ministry of Education, Faculty of Materials Science and Chemistry, China University of Geosciences, Wuhan, 430074, China.

${ }^{2}$ Energy Storage Joint Research Center, Southeast University School of Energy and Environment, Southeast University, Nanjing, 210096, China.

${ }^{3}$ Key Laboratory of Ferro and Piezoelectric Materials and Devices of Hubei Province, Faculty of Physics and Electronic Sciences, Hubei University, Wuhan, 430062, China.

${ }^{4}$ Huazhong University of Science and Technology, Wuhan, 430074, China.

${ }^{5}$ College of Chemistry and Chemical Engineering, Xiamen University, Xiamen, 361005, China.

${ }^{6}$ Institute of High Energy Physics, Chinese Academy of Sciences, 100049, China.

${ }^{7}$ Department of Aero \& Auto Engineering, Loughborough University, Loughborough, LE11 3TU, UK

*Correspondence to: binzhu@kth.se; songhb@cug.edu.cn.

$\dagger$ These authors contributed equally.

Abstract: Tuning semiconductor to fast proton conductor is an emerging methodology to meet demands for rapidly growing proton ceramic fuel cells (PCFCs). The key challenge for PCFCs is the proton conducting electrolyte with sufficient proton conductivity $>0.1$ Siemens per centimeter for low temperatures (300 to 600 Celsius). Herein we present a novel effective methodology to design super proton conductor via a semiconductor heterostructure of $\mathrm{Na}_{x} \mathrm{CoO}_{2} / \mathrm{CeO}_{2}$, where a field-induced metallic state at the interface accelerates proton transportation. We have realized the ionic conductivity of 0.30 Siemens per centimeter and a demonstration for PCFC of 1 Watt per square centimeter at 520 Celsius. Our results bring a new insight into proton transport mechanism by a semiconductor heterostructure methodology, which can also benefit other relevant energy applications by ionic transportation.

One Sentence Summary: Semiconductor interface with a metallic state builds up a super proton transportation highway. 
Main Text: The key challenge for new generation proton ceramic fuel cells (PCFCs) is to develop high proton conducting electrolytes (1-3). Goodenough proposed to develop oxide-ion conductors based on the structural design for solid oxide fuel cells (SOFCs) (4). This approach is to design new oxide-ion conductors by using lower valence cations' doping high ones to create oxygen vacancies for $\mathrm{O}^{2-}$ conductivity, e.g. $\mathrm{Y}^{3+}$ or $\mathrm{Sm}^{3+}$ replaced $\mathrm{Zr}^{4+}$ or $\mathrm{Ce}^{4+}$ in zirconia or ceria fluorite structures. However, it has not yet made alternatives for the conventional yttrium stabilized zirconia (YSZ) electrolyte. A functional triple charge conducting $\mathrm{BaCo}_{0.4} \mathrm{Fe}_{0.4} \mathrm{Zr}_{0.1} \mathrm{Y}_{0.1} \mathrm{O}_{3-\delta}$ (BCFZY) cathode has explored a new promising strategy to bring PCFC as a competitor to SOFC (5), but the conductivities of proton ceramic electrolytes (6-8) are still far below the desired value of $0.1 \mathrm{~S} \mathrm{~cm}^{-1}$. Our target is to develop functional conductors with proton conductivity of $>0.1 \mathrm{~S} \mathrm{~cm}^{-1}$ at $500{ }^{\circ} \mathrm{C}$ to meet the demand of advanced PCFCs. Interfacial ionic transport properties in semiconductor heterostructure and local electric field (LEF) effect have unique advantages, owing to their accessibility and tunability of creating extended functionalities $(9,10)$. Here we introduce p-type $\mathrm{Na}_{x} \mathrm{CoO}_{2}(\mathrm{NCO})$ materials (Table S1) to construct semiconductor heterostructure system with n-type $\mathrm{CeO}_{2}$ (Fig. 1A). The LEF is built to form proton transporting channels at the NCO surface to effectively modulate charge transport property and confine fast ionic mobility in the $\mathrm{NCO} / \mathrm{CeO} 2$ heterostructure interfaces. This methodology is in strong contrast to the traditional doping crystal structures.

To understand the origin of the emergent electronic state in the $\mathrm{NCO} / \mathrm{CeO}_{2}$ heterostructure, the first-principles calculations based on Density Functional Theory (DFT) were performed on three systems: bulk $\mathrm{NCO}$ and $\mathrm{CeO}_{2}$ (Fig. S1), surfaces of the $\mathrm{NCO}$ and $\mathrm{CeO}_{2}$, and an interface of the $\mathrm{NCO} / \mathrm{CeO}_{2}$ (Fig. 1B). The partial density of states (Fig. S2) further discoveries that the interface across a $\mathrm{CoO}_{2}$ layer of $\mathrm{NCO}$ and $\mathrm{Ce}-\mathrm{O}$ layer of $\mathrm{CeO}_{2}$ causes band-bending, with the $d$-orbital electrons dipping below the Fermi level, thereby forming the metallic state. Further the ionic migration energy $(\mathcal{E})$ provides us a new understanding for designing the optimal paths of proton transportation. Though proton may transport through the lattice of $\mathrm{CeO}_{2}$ or layered-structure $\mathrm{NCO}, \varepsilon_{\mathrm{i}}\left(\mathrm{i}=1,2\right.$ respectively for $\mathrm{CeO}_{2}$ and $\mathrm{NCO}$ ) is high due to the structural bonding energy. In contrast, the $\mathrm{H}^{\cdots} \mathrm{NCO}$ could provide a highly conductive path in terms of out-of-plane doping control of the in-plane electronic charge (11). The diffusion barriers are $3.17 \mathrm{eV}\left(\varepsilon_{1}\right)$ for proton migration in $\mathrm{CeO}_{2}, 3.89 \mathrm{eV}\left(\varepsilon_{2}\right)$ in $\mathrm{Na}_{0.6} \mathrm{CoO}_{2}$, and $0.15 \mathrm{eV}\left(\varepsilon_{3}\right)$ at the interface, respectively. The proton barrier energy at the interface is significantly reduced more than 20 times than those of bulk $\mathrm{CeO}_{2}$ and $\mathrm{NCO}$. The interface between the $\mathrm{NCO}$ and $\mathrm{CeO}_{2}$ can provide a weak bonding situation, thus building proton transport highway with much lower migration energy (Fig. 1C).

The heterostructure exhibits a sphere-shape $\mathrm{CeO}_{2}$ cluster epitaxially grown at $\mathrm{NCO}$, forming uniform sphere-cluster-by-layer morphology with a top $\mathrm{CeO}_{2}$ cluster and an $\mathrm{NCO}$ nanosheet (Fig. 2A). The high-resolution image in Fig. 2B demonstrates that (111) plane of cubic $\mathrm{CeO}_{2}$ contacts well with (001) planes of NCO nanosheets. The crystal structure and component have also been characterized (Fig. S3). Especially, the oxygen $K$ edge spectra (Fig. 2C) in different local chemical environments of $\mathrm{NCO} / \mathrm{CeO}_{2}$ further displays an additional peak localized at 539 $\mathrm{eV}$ (peak 2) associated with the interface region. This additional peak is resulting from the unique electronic structure caused by the aggregation of oxygen in the interface region (12). Kelvin probe force microscope (KPFM) measurement is used to characterize the interface properties of $\mathrm{CeO}_{2}$ and $\mathrm{NCO}$ (13-15). The topography spatial map and the corresponding surface potentials of $\mathrm{NCO} / \mathrm{CeO}_{2}$ (Fig. 2D, E) reveal that there are notable changes between interfaces. In an illustrative line scan crossing the interface of $\mathrm{NCO}$ and $\mathrm{CeO}_{2}$ (Fig. 2F), the surface potential difference between $\mathrm{NCO}$ and $\mathrm{CeO}_{2}$ is about $15 \mathrm{mV}$, demonstrating the existence of LEF at the 
$\mathrm{NCO} / \mathrm{CeO}_{2}$ interface, which is also verified by the $\mathrm{NCO} / \mathrm{CeO}_{2}$ heterostructure film device (Fig. 2G) with a clear rectifying effect.

The chemical and structural characterizations of the $\mathrm{NCO} / \mathrm{CeO}_{2}$ hydrogenation process were performed. The hydrogenation is only occurring in the NCO structure with a noticed $\mathrm{H} \cdots \mathrm{O}-\mathrm{Co}$ bond formation (a new peak centered at $1071 \mathrm{~cm}^{-1}$ ) confirmed by in-situ Raman measurement (Fig. 2H, Fig. S4) while no change observed in the $\mathrm{CeO}_{2}$ structure (Fig. 2I). The ex-situ X-ray absorption near-edge spectroscopy (XANES) measurements of the cobalt $K$-edge and Ce L3edge from a pristine and tested $\mathrm{NCO} / \mathrm{CeO}_{2}$ samples are shown in Fig. S5, confirming the hydrogenation process only taking place during the in-situ process.

The demonstration results of the designed $\mathrm{NCO} / \mathrm{CeO}_{2}$ heterostructure in PCFC device are presented in Fig. 3. The pristine NCO is an electron conductor $(16,17)$, does not show any performance in a fuel cell device (Fig. 3A). Pure $\mathrm{CeO}_{2}$ electrolyte due to the existence of oxygen vacancies (Fig. S6), exhibits $300 \mathrm{~mW} \mathrm{~cm}^{-2}$ power output at $520{ }^{\circ} \mathrm{C}$. With the formation of the $\mathrm{NCO} / \mathrm{CeO}_{2}$ heterostructure interfaces, the device reaches $1000 \mathrm{~mW} \mathrm{~cm}{ }^{-2}$ at $520{ }^{\circ} \mathrm{C}$ corresponding to an OCV of $1.07 \mathrm{~V}$ (Fig. 3B) with a good reproducibility, see Fig. S7. Such great enhancement of the power output is attributed to the synergic effects of LEF at the interface and the metallic state of NCO surface, which accelerate the proton transport through the interface of $\mathrm{NCO}$ and $\mathrm{CeO}_{2}$. The $\mathrm{NCO} / \mathrm{CeO}_{2}$ device can even run at $370{ }^{\circ} \mathrm{C}$, and the power density output still maintains above $100 \mathrm{~mW} \mathrm{~cm}{ }^{-2}$ (Fig. 3 B). The high OCV, e.g. $1.07 \mathrm{~V}$ at $520^{\circ} \mathrm{C}$ is agreed to the Nernst theoretical potential, indicating that the ionic transference number is close to unity, so the electron conduction has been suppressed $(18,19)$. Moreover, we have also investigated fuel cells consisting of different $\mathrm{Na}_{x} \mathrm{CoO}_{2}$ composite samples in various $\mathrm{Na}$ contents $(x=0.47,0.55$ and 0.71 ) with the existence of metallic state (Fig. S8). These cells demonstrated high performances of more than $550 \mathrm{~mW} \mathrm{~cm}^{-2}$ at $520^{\circ} \mathrm{C}$ (Fig. S9), which further support the $\mathrm{NCO} / \mathrm{CeO}_{2}$ heterostructure electrolytic function.

The Nyquist plot of the $\mathrm{Na}_{0.6} \mathrm{CoO}_{2} / \mathrm{CeO}_{2}(2: 8)$ cell under OCV condition measured at $490{ }^{\circ} \mathrm{C}$ shown in Fig. 3C. The total ohmic area specific resistance (ASR) of this cell is remarkably low, $0.26 \Omega \mathrm{cm}^{2}$ for the $\mathrm{NCO} / \mathrm{CeO}_{2}$ thickness of $400 \mu \mathrm{m}$, which is comparable with the target value $\left(0.15 \Omega \mathrm{cm}^{2}\right)$ for a $15 \mu \mathrm{m}$ thick electrolyte used for high performance PCFCs. The Nyquist plot is modeled by an equivalent circuit with an ohm resistor $\left(R_{0}\right)$ and serial elements each consisting with a resistor $\left(\mathrm{R}_{i}, i=1,2\right)$, and a constant phase element $\left(\mathrm{CPE}_{i}, i=1,2\right)$, as summarized in Table S2. These two semicircles (Fig. 3C) originate from the electrode polarization resistances. The corresponding ionic conductivity of $\mathrm{NCO} / \mathrm{CeO}_{2}$ measured at fuel-cell condition is presented in Fig. 3 D, and compared with several other best oxygen-ion and proton conducting electrolyte materials $(20-22)$. The $\mathrm{NCO} / \mathrm{CeO}_{2}$ exhibits the highest ionic conductivity, $0.30 \mathrm{~S} \mathrm{~cm}^{-1}$ at $520{ }^{\circ} \mathrm{C}$ $\left(0.24 \mathrm{~S} \mathrm{~cm}^{-1}\right.$ at $\left.500{ }^{\circ} \mathrm{C}\right)$, also the lowest activation energy, $0.27 \mathrm{eV}$.

The proton conduction in $\mathrm{NCO} / \mathrm{CeO}_{2}$ was further verified from two experiment approaches. The first is to construct a fuel cell device with proton-conducting $\mathrm{BaZr}_{0.8} \mathrm{Y}_{0.2} \mathrm{O}_{3-\delta}(\mathrm{BZY})$ filter (Fig. S10), where the $\mathrm{NCO} / \mathrm{CeO}_{2}$ electrolyte was sandwiched between two BZY ion-filter layers, only allowing protons passing through and determining $\mathrm{H}^{+}$transport property (23). The device with BZY filters enables to achieve $890 \mathrm{~mW} \mathrm{~cm}^{-2}$ at $520^{\circ} \mathrm{C}$ (Fig. $3 \mathbf{~ E}$ ), which is very close to the power output $1000 \mathrm{~mW} \mathrm{~cm}{ }^{-2}$ of the $\mathrm{NCO} / \mathrm{CeO}_{2}$ fuel cell. The difference is attributed to the ohmic losses caused by two additional BZY layers with limited proton conductivity that is significantly lower than that of the $\mathrm{NCO} / \mathrm{CeO}_{2}$, see Fig. $3 \mathrm{D}$. In addition, polarization losses coming from additional contacting interfaces between the $\mathrm{BZY}$ and $\mathrm{NCO} / \mathrm{CeO}_{2}$ are also introduced. This result 
clearly proves proton-dominating conduction in the $\mathrm{NCO} / \mathrm{CeO}_{2}$ heterostructure electrolyte. Another experiment is to measure the proton conduction isotopic effect, where conductivities of the $\mathrm{NCO} / \mathrm{CeO}_{2}$ were measured in 5\% $\mathrm{H}_{2}-95 \% \mathrm{Ar}$ and $5 \% \mathrm{D}_{2}-95 \% \mathrm{Ar}$ at various temperatures, respectively. The associated conductivities are significantly increased from $5 \% \mathrm{D}_{2}$ to $5 \% \mathrm{H}_{2}$, exhibiting a clear H/D isotope effect (Fig. 3F). This provides further a direct evidence of proton conduction in the designed material (24).

Compared with the best proton conducting $\mathrm{BaZr}_{0.4} \mathrm{Ce}_{0.4} \mathrm{Y}_{0.1} \mathrm{Yb}_{0.1} \mathrm{O}_{3}$ thin film electrolyte fuel cell $\left(500 \mathrm{~mW} \mathrm{~cm}^{-2}\right.$ at $\left.500{ }^{\circ} \mathrm{C}\right)$, the $\mathrm{NCO} / \mathrm{CeO}_{2}$ device shows $800 \mathrm{~mW} \mathrm{~cm}{ }^{-2}$ at $500{ }^{\circ} \mathrm{C}$ and $1000 \mathrm{~mW}$ $\mathrm{cm}^{-2}$ at $520^{\circ} \mathrm{C}$ (Fig. 3 B). In addition, $\mathrm{NCO} / \mathrm{CeO}_{2}$ as electrolytes in different molar ratios also show significant outputs (Fig. S11). The $\mathrm{NCO} / \mathrm{CeO}_{2}$ heterostructure has demonstrated promising advantages for PCFCs $(25,26)$. The durability of the $\mathrm{NCO} / \mathrm{CeO}_{2}$ device was tested under 100 $\mathrm{mA} \mathrm{cm}{ }^{-2}$ during a 100-h period, of which the operation voltage was further improved from $0.9 \mathrm{~V}$ to around $1.0 \mathrm{~V}$ by introducing an anode buffer layer (ABL) (Fig. S12). The ABL can effectively enhance device performance and durability. This lab test can be further improved by exploring optimized electrode materials and device technology with more engineering efforts.

Theoretical calculations further reveal the proton conduction mechanism as illustrated in Fig. 4, where the charge density difference distributions of $\mathrm{NCO} / \mathrm{CeO}_{2}$ interface are presented in Fig. 4A. At $\mathrm{NCO} / \mathrm{CeO}_{2}$ interface, the unbalanced charge distribution between $\mathrm{Ce}-\mathrm{O}$ and $\mathrm{Co}-\mathrm{O}$ layers induces a LEF within the interface region; around oxygen vacancies of $\mathrm{CeO}_{2}$ and sodium vacancies of $\mathrm{NCO}$ can further cause an in-plane LEF, where interfacial potential is verified by the KPFM (Fig. 2F) and the LEF through $I-V$ curve of $\mathrm{NCO} / \mathrm{CeO}_{2}$ thin film device (Fig. 2G). Proton transporting states and paths are illustrated through Fig. 4 B-C. Proton intercalation leads to a dramatic shift of spectra weight of Co $3 d$ and Ce $4 f$ bands towards higher energy. Correspondingly, distributed orbitals cover a wide range from $\mathrm{E}_{\mathrm{F}}-3 \mathrm{eV}$ to $\mathrm{E}_{\mathrm{F}}+1 \mathrm{eV}$, indicating the proton transporting path with a lower barrier and resistance. Nudged elastic band (NEB) calculations were carried out to understand proton migration pathways, the energy diagram of diffusion of $\mathrm{H}$ at interface (Fig. 4D) reveals the lowest energy barrier between proton and NCO. This is the optimal migration pathway for proton moving from $\mathrm{CeO}_{2}$ to $\mathrm{NCO}$ surface. During transporting process, the proton driven by the LEF could incorporate with lattice oxygen ion and hop through the oxygen vacancy of $\mathrm{CeO}_{2}$ (i: Initial state) forming $\mathrm{H}-\mathrm{O}-\mathrm{Ce}$ bond (a bond length of $0.98 \AA$ ). Meanwhile, the LEF is confined within the heterostructure interface, which drives protons from the positively charged $\mathrm{CeO}_{2}$ to the negatively charged $\mathrm{NCO}$ surface. (ii: Transition state) (Fig. 4E). Once proton is close to $\mathrm{NCO}, \mathrm{Na}$ experiences a large distortion leading to a strong repulsive force to proton. This causes a deformation of $\mathrm{H} \cdots \mathrm{O}-\mathrm{Co}$ (bond length $1.04 \AA$ ) to $\mathrm{H} \cdots \mathrm{O}-\mathrm{Ce}$ bond $(1.70 \AA)$. In addition, the barrier is too high for protons to transport in the NCO and $\mathrm{CeO}_{2}$ structure, so protons are confined in the $\mathrm{NCO} / \mathrm{CeO}_{2}$ interface. Finally, protons spontaneously flow along the superior proton channel resulted from the LEF-induced metallic state of NCO surface (iii: Final state), of which the active energy is $0.15 \mathrm{eV}$, being much lower than those of the bulk $\mathrm{CeO}_{2}(3.17 \mathrm{eV})$ and $\mathrm{NCO}(3.89 \mathrm{eV})$. Such superior proton conduction is attributed to a synergic effect between LEF and metallic state of NCO surface to greatly accelerate proton transportation.

We have presented a new approach to design and develop super proton transport with accelerating channels through a unique field-induced metallic state in the $\mathrm{NCO} / \mathrm{CeO}_{2}$ semiconductor heterostructure. The ever-high proton conductivity, $0.1-0.3 \mathrm{~S} \mathrm{~cm}^{-1}$ (at 370 $520^{\circ} \mathrm{C}$ ) has been realized in this system. The $\mathrm{NCO} / \mathrm{CeO}_{2}$ fuel cell has exhibited a remarkable 
power density of $1000 \mathrm{~mW} \mathrm{~cm}{ }^{-2}$ at $520^{\circ} \mathrm{C}$. It presents a general methodology based on unique interfacial structure and property to develop new functional semiconductor heterostructures. More broadly, this work lays the theoretical and experimental foundations for designing and exploiting novel materials in energy applications.

\section{References and Notes:}

1. Duan, C. C. et al., Nature 557, 217-222 (2018).

2. Choi, S. et al., Nat. Energy 3, 202-210 (2018).

3. Duan, C., et al., Nat. Energy 4, 230-240(2019).

4. Goodenough, J. B., Nature 404, 821-823 (2000).

5. Duan, C. C., et al., Science 349, 1321-1326 (2015).

6. Lan, R., Tao, S. W., Adv. Energy Mater. 4, 1301683-1301689 (2014).

7. Kim, I. H., et al., J Mater. Chem. A 7, 21321 (2019).

8. Zhou, Y., et al., Nature 534, 231-234 (2016).

9. Zheng, Y., et al., Adv. Mater. 29, 1700396 (2017).

10. Xia, T., et al., Nano Lett. 13, 5289-5296 (2013).

11. Bañobre-López, M. et al., Chem. Mater. 17, 1965-1968 (2005).

12. Wang, B. Y. et al. J. Mater. Chem. A 4, 15426-15436 (2016).

13. Liscio, A.et al., Adv. Funct. Mater. 16, 1407-1416 (2006).

14. Bocquet, F., et al., Phys. Rev. B. 78, 035410 (2008).

15. Melzer, C.et al., Adv. Mater. 25, 4315-4319 (2013).

16. Berthelot, R., Carlier, D., Delmas, C. Nat. Mater. 10, 74 (2010).

17. Takada, K., et al., Adv. Mater. 16, 1901-1905 (2010).

18. Asghar, M.I., et al., Nano Energy 53, 391-397 (2018).

19. Zhu, B., et al., Nano Energy 19, 156-164 (2016).

20. Jacobson, A. J. Chem. Mater. 22, 660-674 (2010).

21. Esposito, V., Traversa, E., J. Am. Ceram. Soc. 91, 1037-1051 (2008).

22. Pergolesi, D., et al. Nat. Mater. 9, 846-852 (2010).

23. Wu, Y. et al., ACS Appl. Energy Mater. 1, 580-588 (2018).

24. Xing, Y., et al., ACS Energy Lett. 4, 2601-2607 (2019).

25. Garcia-Barriocanal, J., et al., Science 321, 676-680 (2008).

26. Zhao, C., et al., Energy Environ. Sci.13, 53-85 (2020).

27. Ravel, B., et al., J. Synchrotron Radiat. 12, 537-541 (2005).

28. Koningsberger, D. C., Prins, R. (Eds.) X-ray Absorption: Principles, Applications, Techniques of EXAFS, SEXAFS, and XANES (Wiley, 92, 1988). 
29. Rehr, J. J., et al., Rev. Mod. Phys. 72, 621-654 (2000).

30. Kresse, G., Hafner, J. Phys. Rev. B. 47, 558- 561 (1993).

31. Kresse, G., et al., Comput. Mater. Sci. 6, 15-50 (1996).

32. Kresse, G., Joubert, D. Phys. Rev. B. 59, 1758-1775 (1999).

33. Perdew, J. P., et al., Phys. Rev. Lett. 77, 3865-3868 (1996).

34. Dudarev, S. L., et al., Phys. Rev. B. 57, 1505- 1509 (1998).

35. Henkelman, G., et al., Chem. Phys. 111, $7010-7022$ (1999).

36. Yang, J., et al., J. Phys. Chem. C. 114, 111-119 (2010).

37. Patil, U. M., et al., Sci. Rep. 6, 35490 (2016).

\section{Acknowledgments:}

We sincerely appreciate Dr. B.Y. Wang's group from Hubei University for verifying fuel cell results. We acknowledge Prof. Z.Y. Huang from Nanyang Technological University and Dr. J. $\mathrm{Su}$ from Center for Nanoscale Characterization \&

Devices, WNLO of the Huazhong University of Science and Technology (HUST) for highresolution TEM characterization and discussion. We acknowledge Prof. J. Tang from Huazhong University of Science and Technology for helpful discussion.

Funding: We acknowledge the support from the National Natural Science Foundation of China (NSFC, grant Nos. 51774259, 51772080).

Authors contributions: Y.W., H.B.S. and B.Z. conceived the idea, designed the experiments and analyzed the data. L. L. and Q.S. carried out most of the characterizations and device optimizations. M.H. performed the theoretical simulations and analyzed the results. Y.W., M.H., C.C, L.L. Q.S., J.S.K., H-B.S. and B.Z. participated in the device optimization and data analysis. J.W. and J.F.L. carried out Raman characterizations and analyzed the results. L.R.Z. carried out XANES characterizations and analyzed the results. M.A. verified fuel cell results. Y.W., H-B.S. and B.Z. wrote the paper; all the authors commented on the manuscript.

Competing interests: The authors declare no competing interests.

Data and materials availability: All data are available in the manuscript or the supplementary materials.

\section{Supplementary Materials:}

Materials and Methods

Supplementary Text

Figs. S1-S12

Tables S1-S3 
Fig. 1. Design of the $\mathrm{NCO} / \mathrm{CeO}_{2}$ heterostructure functionalities for fast proton migration. A, Schematic of the $\mathrm{NCO} / \mathrm{CeO}_{2}$ fuel cell and its operation mechanism (Local electric field built at the $\mathrm{NCO} / \mathrm{CeO}_{2}$ interface from $\mathrm{CeO}_{2}$ to $\mathrm{NCO}$ side confines proton along $\mathrm{NCO}$ surface). $\mathbf{B}$, total density of states (DOS) of surface of $\mathrm{CeO}_{2}, \mathrm{NCO}$ and $\mathrm{Na}_{x} \mathrm{CO}_{2}(x=0.60) / \mathrm{CeO}_{2}$ interface. $\mathrm{C}, \mathrm{CeO}_{2}$ lattice with (111) plane, interface of the $\mathrm{NCO} / \mathrm{CeO}_{2}$ heterostructure, and $\mathrm{NCO}$ layer with (001) plane with different proton migration activation energies, $\varepsilon_{1}, \varepsilon_{2}, \varepsilon_{3}$, respectively.

Fig. 2. Characterizations of $\mathrm{NCO} / \mathrm{CeO}_{2}$. A, Transmission electron microscopy (TEM) image. B, High resolution TEM image. C, Oxygen $K$ edge spectra in different local chemical environments. D, Atomic force microscopy image and $\mathbf{E}$ scanning Kelvin probe force microscopy (KPFM) image of $\mathrm{NCO} / \mathrm{CeO}_{2}$. The scanning area is $2.5 \mu \mathrm{m} \times 2.5 \mu \mathrm{m}$. $\mathbf{F}$, Contact potential difference along the solid white line drawn in $(\mathbf{E})$ and (F). g, $I-V$ curve of $\mathrm{NCO} / \mathrm{CeO}_{2}$ heterostructure deposited on ITO/glass substrate with Au electrodes. In-situ and ex-situ Raman spectra of $\mathrm{NCO}(\mathbf{H})$ and $\mathrm{CeO}_{2}$ (I) underair and $\mathrm{H}_{2}$ atmospheres.

Fig. 3. A, $I-V$ and $I-P$ characteristics of $\mathrm{NCO}, \mathrm{CeO}_{2}, \mathrm{NCO} / \mathrm{CeO}_{2}$ device operated at $520{ }^{\circ} \mathrm{C}$. $\mathrm{B}, I-V$ and $I-P$ characteristics of the $\mathrm{NCO} / \mathrm{CeO}_{2}$ device operated at various temperatures. C, Nyquist plot obtained under $\mathrm{OCV}$ condition at $490{ }^{\circ} \mathrm{C}$ for a $\mathrm{Ni} / \mathrm{NCAL} / \mathrm{NCO} / \mathrm{CeO}_{2} / \mathrm{NCAL} / \mathrm{Ni}$ cell. $\mathbf{D}$, The ionic conductivity of $\mathrm{NCO} / \mathrm{CeO}_{2}$ compared with the best oxygen-ion-conducting electrolytes (dashed lines) and proton conductor (solid lines). E, $I-V$ and $I-P$ characteristics of the $\mathrm{NCO} / \mathrm{CeO}_{2}(2: 8)$ device operated at various temperatures with proton filters. F, Temperature dependence of conductivities in $\mathrm{NCO} / \mathrm{CeO}_{2}(2: 8)$ device operated in $5 \% \mathrm{H}_{2}-95 \% \mathrm{Ar}$ and $5 \% \mathrm{D}_{2}-95 \%$ Ar at various temperatures.

Fig. 4. Proton transporting path. $\mathbf{A}$, charge density differences of $\mathrm{NCO} / \mathrm{CeO}_{2}$ interface. $\mathbf{B}, \mathbf{C}, \mathbf{D}$, the energy diagram of diffusion of $\mathrm{H}$ at $\mathrm{NCO}-\mathrm{CeO}_{2}$ interface. $\mathbf{E}$, the corresponding charge transfer behavior in $\mathrm{NCO} / \mathrm{CeO}_{2}$ interface area. i), initial state, ii), transition state, and iii), final state of $\mathrm{H}$ absorption in $\mathrm{NCO} / \mathrm{CeO}_{2}$ interface with $\mathrm{Na}$ vacancy. 


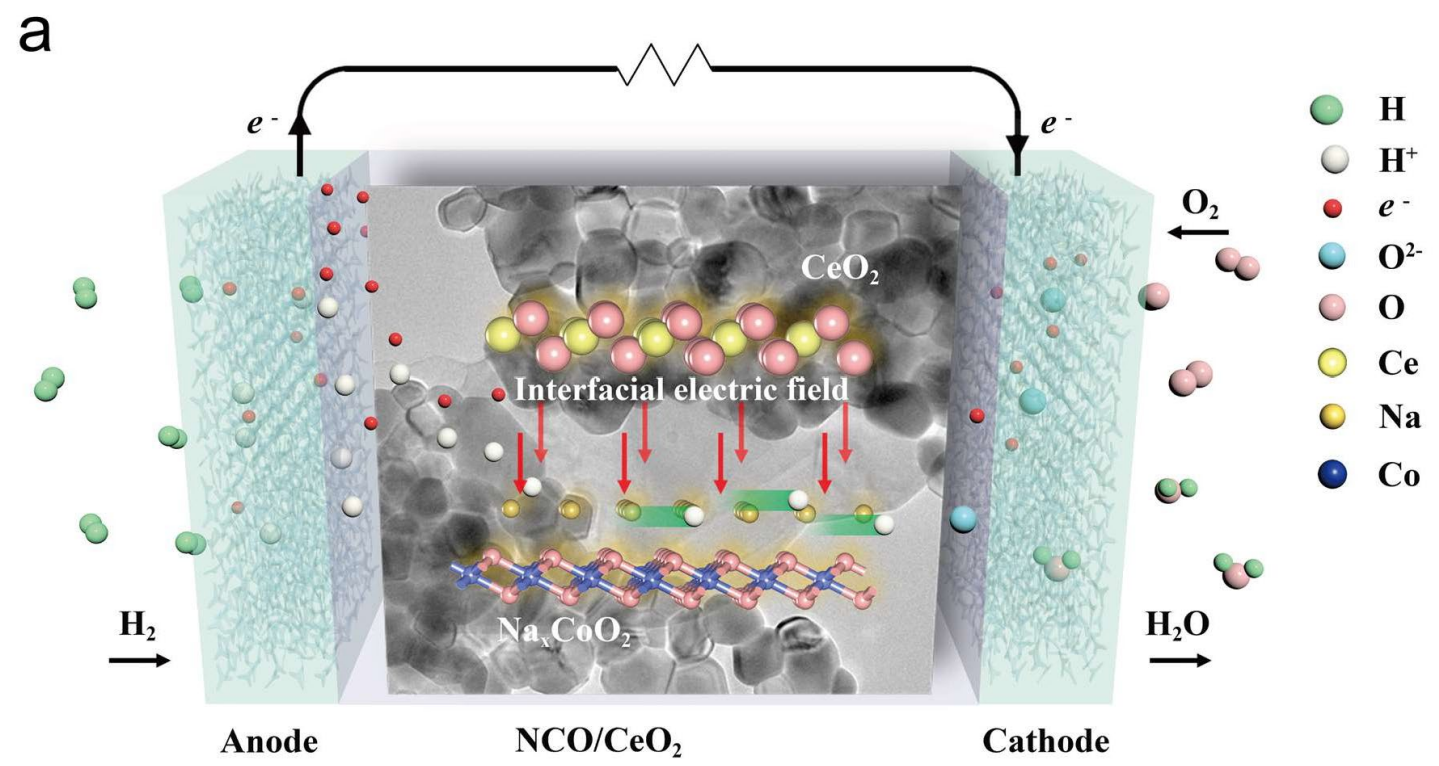

b
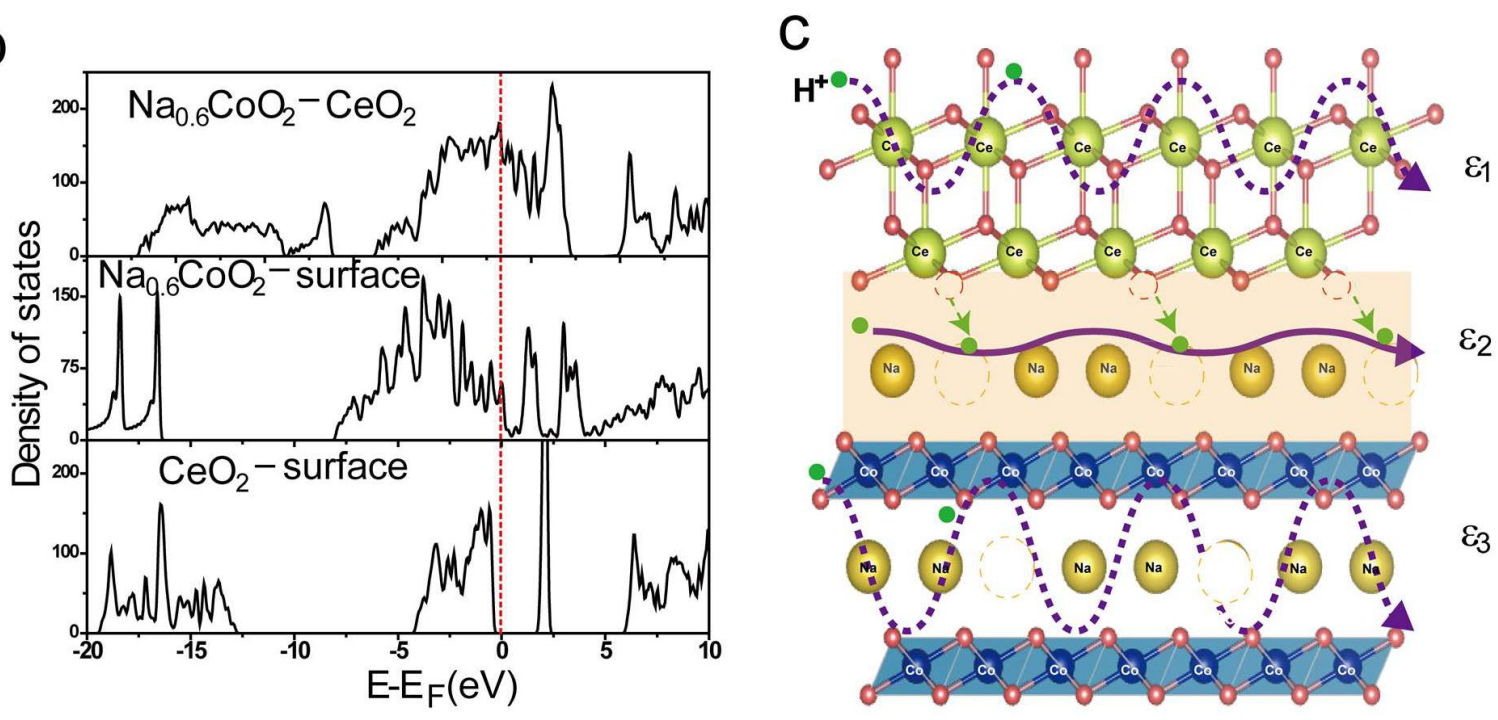

Fig. 1. Design of the $\mathrm{NCO} / \mathrm{CeO}_{2}$ heterostructure functionalities for fast proton migration. A Schematic of the $\mathrm{NCO} / \mathrm{CeO}_{2}$ fuel cell and its operation mechanism (Local electric field built at the $\mathrm{NCO} / \mathrm{CeO}_{2}$ interface from $\mathrm{CeO}_{2}$ to $\mathrm{NCO}$ side confines proton along $\mathrm{NCO}$ surface). $\mathbf{B}$, total density of states (DOS) of surface of $\mathrm{CeO}_{2}, \mathrm{NCO}$ and $\mathrm{Na}_{x} \mathrm{CO}_{2}(x=0.60) / \mathrm{CeO}_{2}$ interface. $\mathrm{C}, \mathrm{CeO}_{2}$ lattice with (111) plane, interface of the $\mathrm{NCO} / \mathrm{CeO}_{2}$ heterostructure, and $\mathrm{NCO}$ layer with (001) plane with different proton migration activation energies, $\varepsilon_{1}, \varepsilon_{2}, \varepsilon_{3}$, respectively. 
A

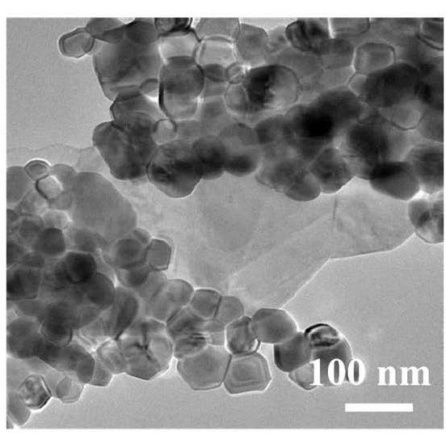

D
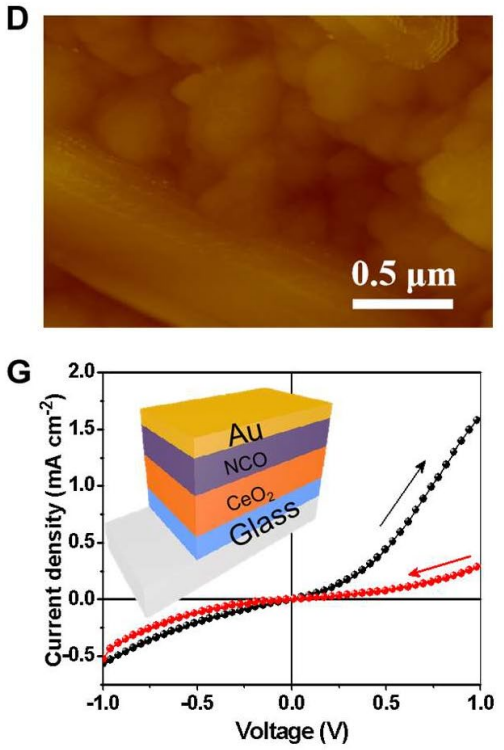

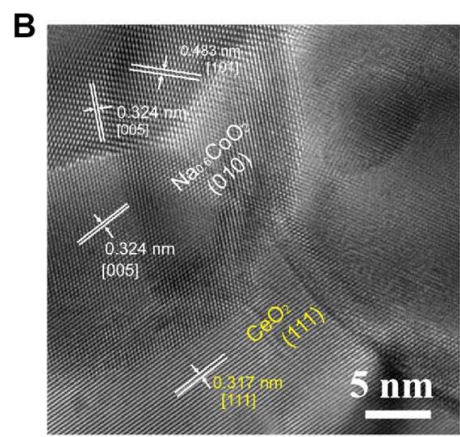

E
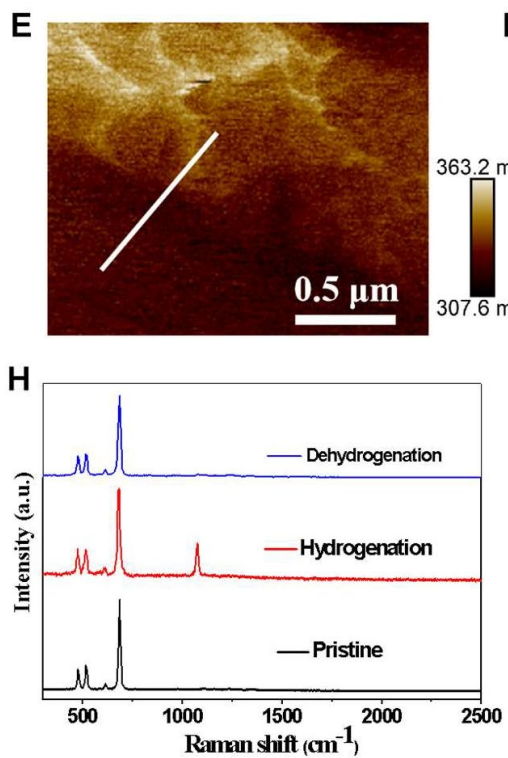
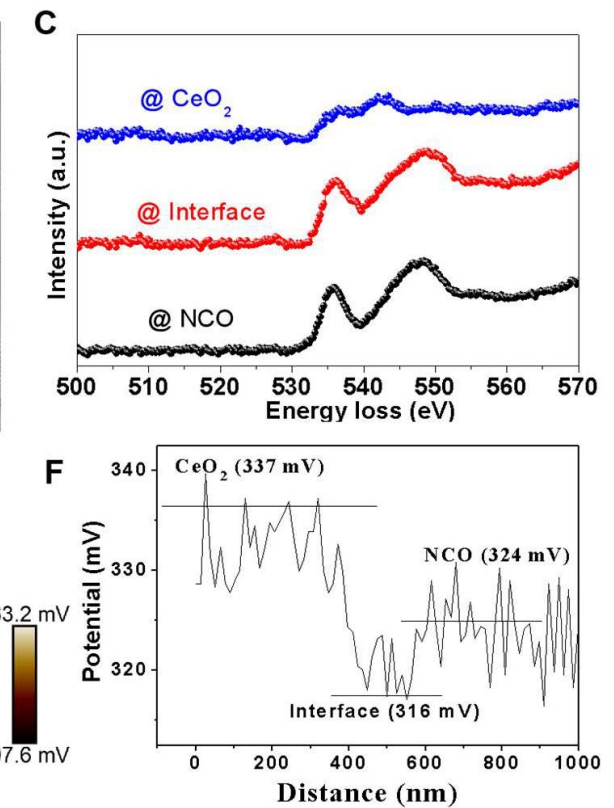

1

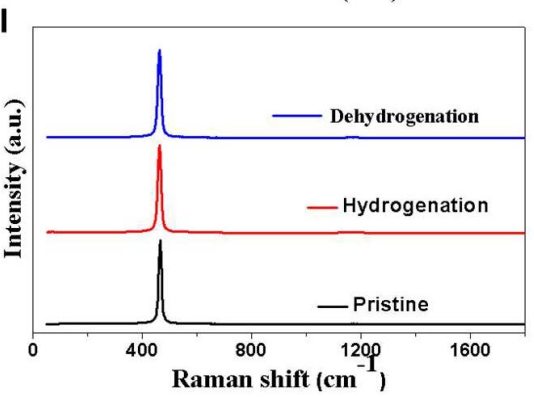

Fig. 2. Characterizations of $\mathrm{NCO} / \mathrm{CeO}_{2}$. A, Transmission electron microscopy (TEM) image. B, High resolution TEM image. C, Oxygen $K$ edge spectra in different local chemical environments. D, Atomic force microscopy image and $\mathbf{E}$ scanning Kelvin probe force microscopy (KPFM) image of $\mathrm{NCO} / \mathrm{CeO}_{2}$. The scanning area is $2.5 \mu \mathrm{m} \times 2.5 \mu \mathrm{m}$. F, Contact potential difference along the solid white line drawn in $(\mathbf{E})$ and (F). $\mathbf{g}, I-V$ curve of $\mathrm{NCO} / \mathrm{CeO}_{2}$ heterostructure deposited on ITO/glass substrate with Au electrodes. In-situ and ex-situ Raman spectra of $\mathrm{NCO}(\mathbf{H})$ and $\mathrm{CeO}_{2}(\mathbf{I})$ under air and $\mathrm{H}_{2}$ atmospheres. 


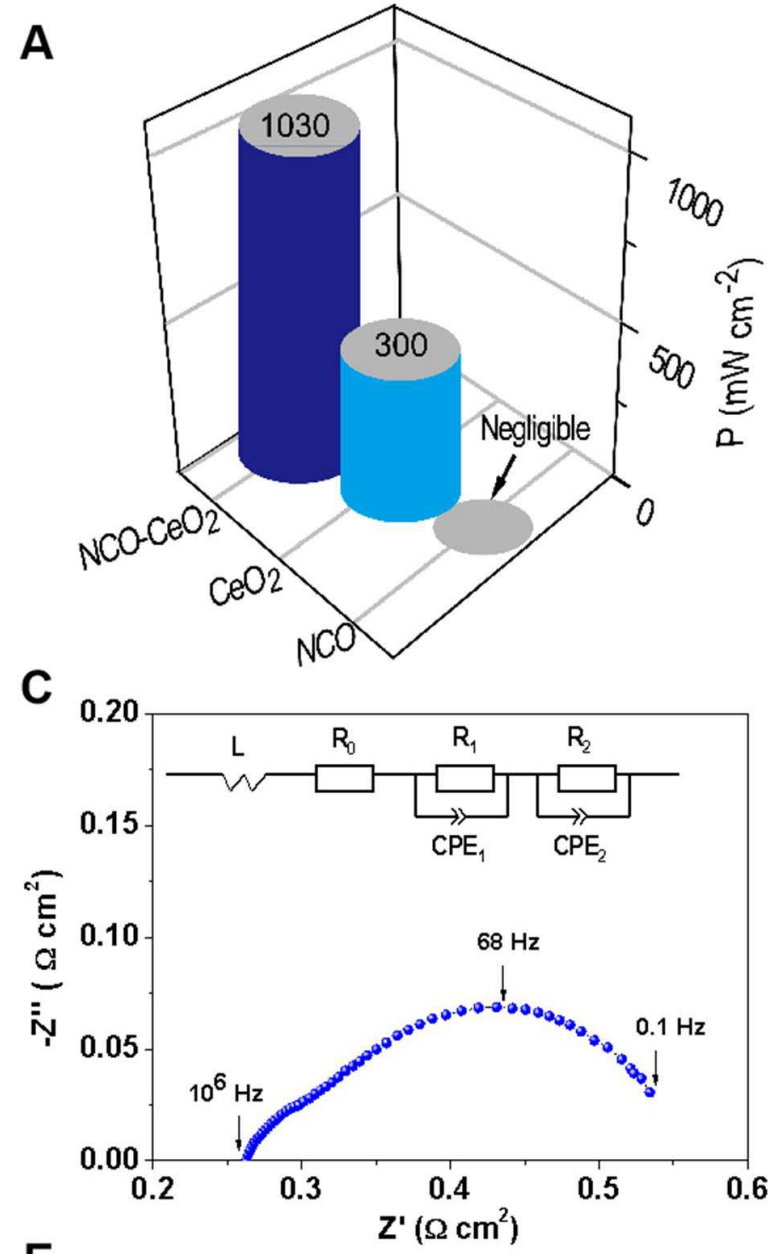

E

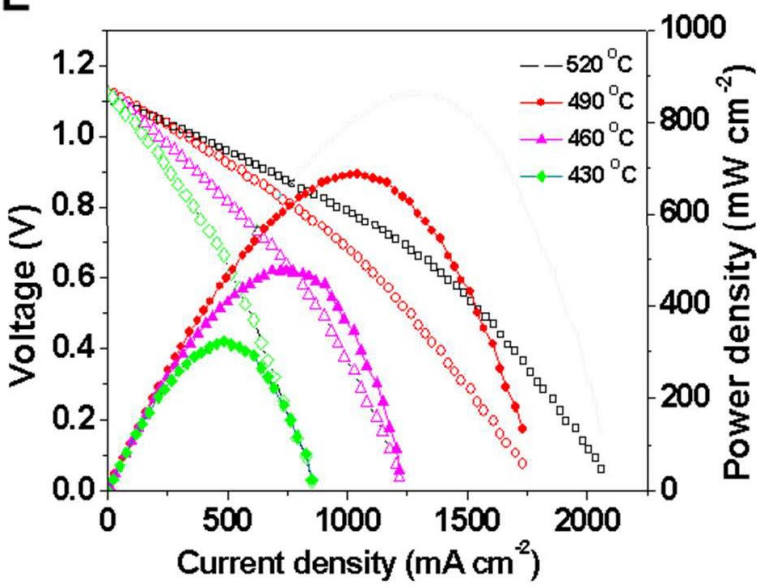

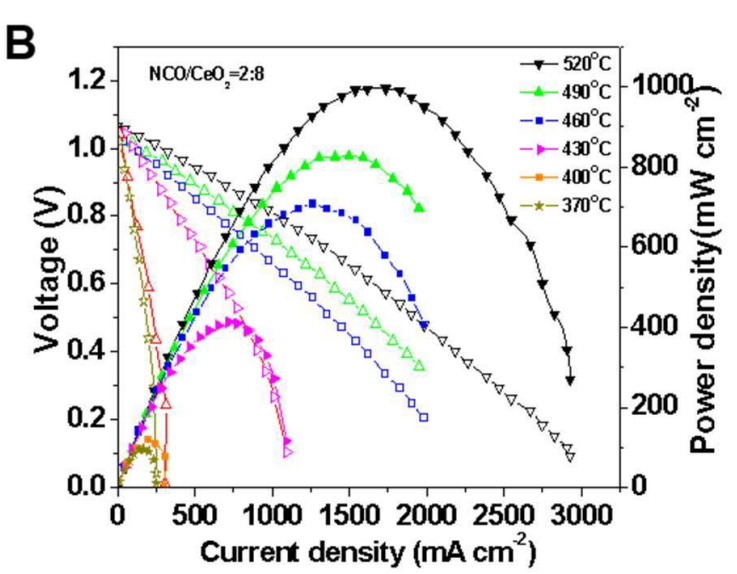

Temperature $\left({ }^{\circ} \mathrm{C}\right)$

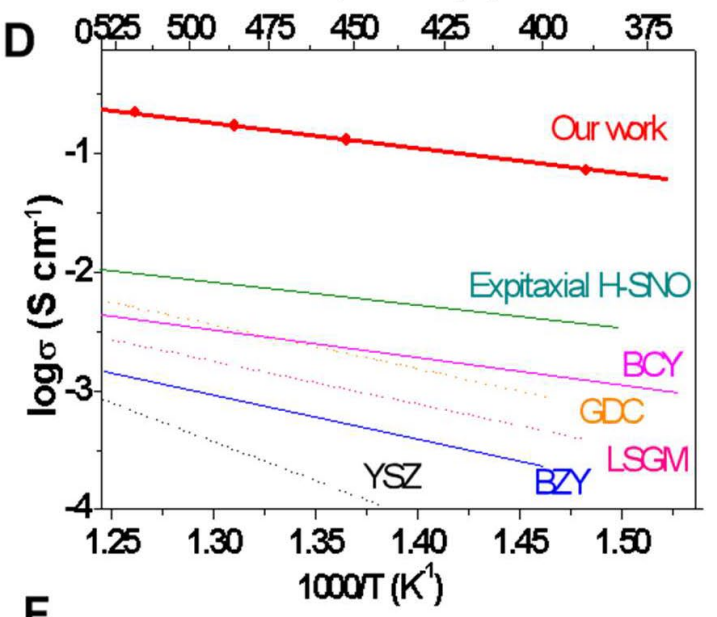

F

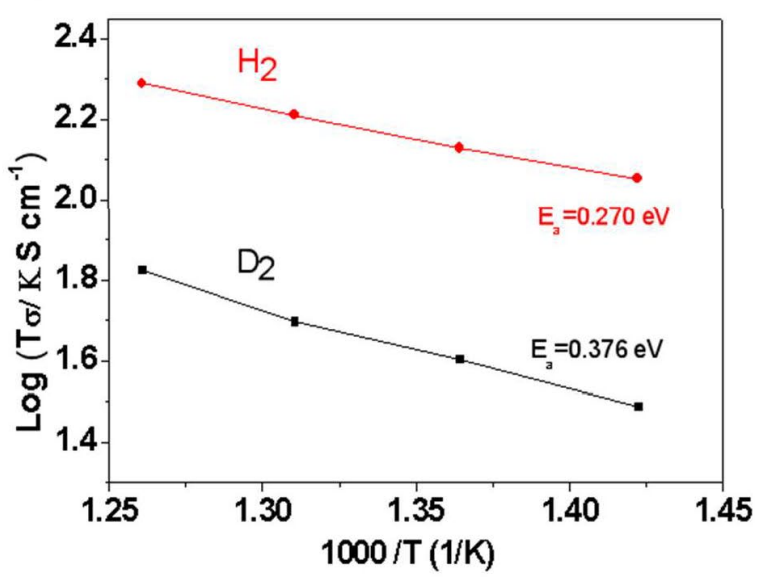

Fig. 3. A, $I-V$ and $I-P$ characteristics of $\mathrm{NCO}, \mathrm{CeO}_{2}, \mathrm{NCO} / \mathrm{CeO}_{2}$ device operated at $520{ }^{\circ} \mathrm{C}$. B, $I-V$ and $I-P$ characteristics of the $\mathrm{NCO} / \mathrm{CeO}_{2}$ device operated at various temperatures. $\mathbf{C}$, Nyquist plot obtained under $\mathrm{OCV}$ condition at $490^{\circ} \mathrm{C}$ for a Ni/NCAL/ NCO/CeO $/ 2 / \mathrm{NCAL} / \mathrm{Ni}$ cell. D, The ionic conductivity of $\mathrm{NCO} / \mathrm{CeO}_{2}$ compared with the best oxygen-ion-conducting electrolytes (dashed lines) and proton conductor (solid lines). E, $I-V$ and $I-P$ characteristics of the $\mathrm{NCO} / \mathrm{CeO}_{2}(2: 8)$ device operated at various temperatures with proton filters. F, Temperature dependence of conductivities in $\mathrm{NCO} / \mathrm{CeO}_{2}(2: 8)$ device operated in $5 \% \mathrm{H}_{2}-95 \% \mathrm{Ar}$ and $5 \% \mathrm{D}_{2}-95 \% \mathrm{Ar}$ at various temperatures. 

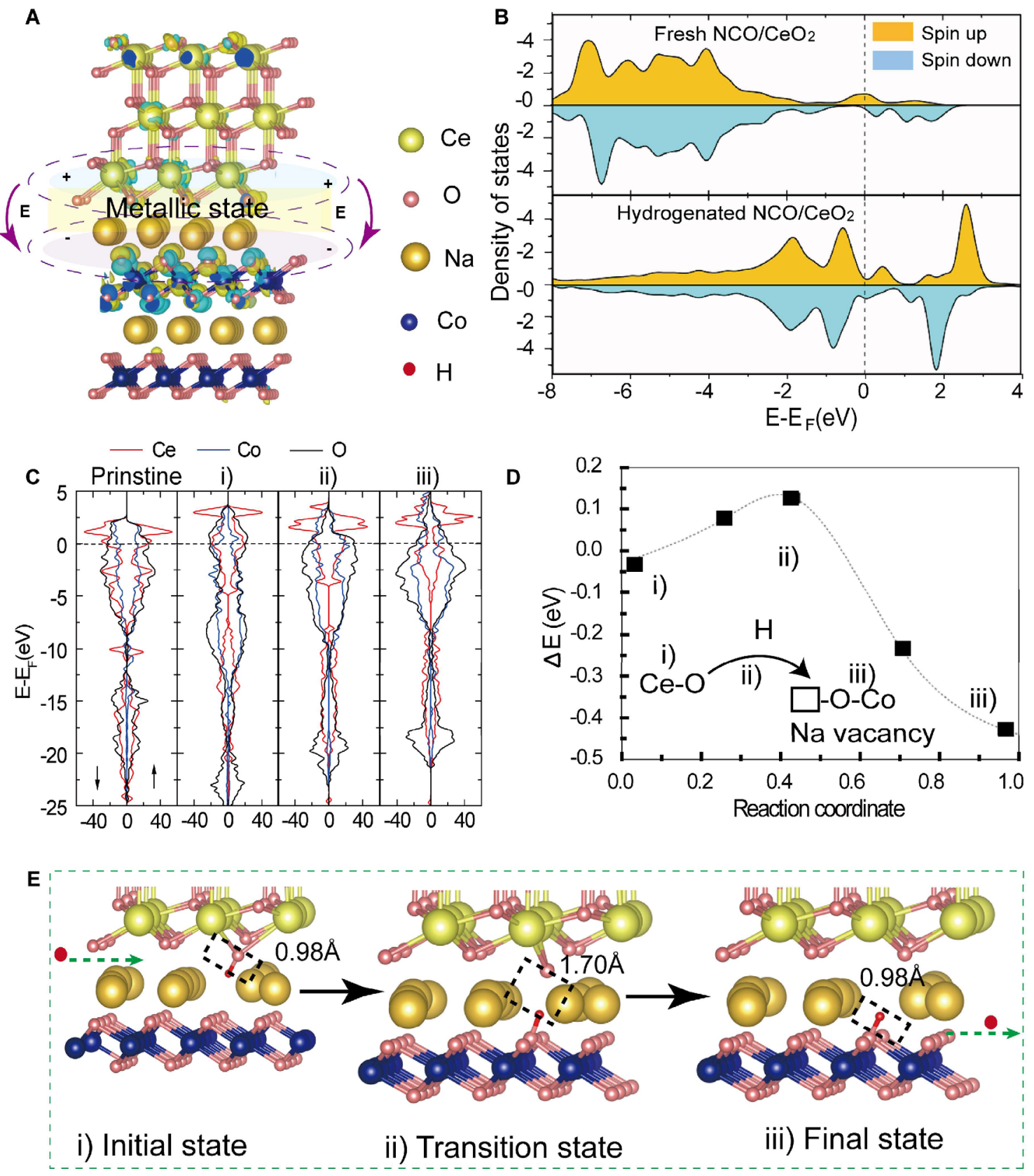

Fig. 4. Proton transporting path. A, charge density differences of $\mathrm{NCO} / \mathrm{CeO}_{2}$ interface. $\mathbf{B}, \mathbf{C}$, $\mathbf{D}$, the energy diagram of diffusion of $\mathrm{H}$ at $\mathrm{NCO}-\mathrm{CeO}_{2}$ interface. $\mathbf{E}$, the corresponding charge transfer behavior in $\mathrm{NCO} / \mathrm{CeO} 2$ interface area. i), initial state, ii), transition state, and iii), final state of $\mathrm{H}$ absorption in $\mathrm{NCO} / \mathrm{CeO}_{2}$ interface with $\mathrm{Na}$ vacancy. 